\title{
Physical rehabilitation in Iran after international sanctions: explored findings from a qualitative study
}

Saeed Shahabi i* (D), Ahmad Ahmadi Teymourlouy², Hosein Shabaninejad ${ }^{3}$, Mohammad Kamali ${ }^{4}$, Kamran Bagheri Lankarani ${ }^{1}$ and Parviz Mojgani ${ }^{5}$

\begin{abstract}
Background: Although the main aims of sanctions are the political and economic pressures on governments, literature has demonstrated the harsh effects of sanctions on the general public, especially on the patients, poor and disabled people. Since the international sanctions regime negatively affected almost all dimensions of Iran's health sector, this qualitative study was conducted to investigate the situation of the physical rehabilitation sector after these sanctions.

Methods: This qualitative study was conducted from January 2019 to June 2019 in Iran using Skype, telephone, and face-to-face in-depth semi-structured interviews. Purposive and snowball sampling approaches were used to identify the participants. Also, framework analysis approach was applied to analyze the collected data.

Results: In total, 38 individuals including health policy-maker, faculty member, rehabilitation expert, Physiotherapist, Occupational therapist, and Orthotist/Prosthetist, were involved in the study. Based on our findings, a number of challenges facing the Iranian physical rehabilitation sector during the international sanctions period included: 1) socioeconomic challenges (inadequate funding, rising inflation rate, high unemployment rate, catastrophic expenditures, and inappropriate employment status of practitioners); 2) education challenges (decreased international collaboration and shortage of training devices and materials); 3 ) international challenges (rising issues in accessing services for patients from neighborhood countries); and 4) service delivery challenges (shortage of raw materials for producing the orthoses and prostheses, hardening of the importing the needed equipment, inappropriate infrastructures, and impossibility to use external assistance).

Conclusion: After international sanctions, the Iranian physical rehabilitation sector has faced considerable multifaceted challenges. Therefore, the international community must be aware of the situation and be concerned about the irreparable consequences.
\end{abstract}

Keywords: Sanctions, Embargoes, Physical rehabilitation, Health policy, Qualitative study

\footnotetext{
* Correspondence: Saeedshahabi1@gmail.com

${ }^{1}$ Health Policy Research Center, Institute of Health, Shiraz University of Medical Sciences, Shiraz, Iran

Full list of author information is available at the end of the article
}

(c) The Author(s). 2020 Open Access This article is licensed under a Creative Commons Attribution 4.0 International License, which permits use, sharing, adaptation, distribution and reproduction in any medium or format, as long as you give appropriate credit to the original author(s) and the source, provide a link to the Creative Commons licence, and indicate if changes were made. The images or other third party material in this article are included in the article's Creative Commons licence, unless indicated otherwise in a credit line to the material. If material is not included in the article's Creative Commons licence and your intended use is not permitted by statutory regulation or exceeds the permitted use, you will need to obtain permission directly from the copyright holder. To view a copy of this licence, visit http://creativecommons.org/licenses/by/4.0/. The Creative Commons Public Domain Dedication waiver (http://creativecommons.org/publicdomain/zero/1.0/) applies to the data made available in this article, unless otherwise stated in a credit line to the data. 


\section{Introduction}

Sanctions and embargoes are designated as powerful political instruments to affect the economic activities of the targeted nation to force a change in the state's behaviors and policies [1]. Following Iran's Islamic Revolution and holding hostage of the U.S. diplomats at the U.S. embassy in Tehran in 1979, the former U.S. President ordered the initial sanctions against Iran [2]. Since then, several sanction regimes were imposed, especially during 2006-2010, in which multilateral sanctions were considered with the United Nations Security Council and Council of the European Union [3]. In response to this situation, Iran and the P $5+1$ (the five permanent members of the United Nations Security Council plus Germany) had intensive negotiations to lifting Iran's nuclear sanctions, and finally, an agreement called the Joint Comprehensive Plan of Action (JCPOA) was established in July 2015. However, the newly elected U.S. President repealed the agreement and reimposed the U.S. sanctions against Iran 3 years later in November 2018 [4]. In fact, given that the main focus of these sanctions has been to reduce Iranian oil revenues and restrict the international activities of the Central Bank of Iran, such limited cooperation with other countries has had significant effects on various social and economic dimensions of Iran [5].

Although the main aims of sanctions are the political and economic pressures, previous literature has shown the harsh effects of sanctions on the general public, especially on the patients, poor and disabled people, with direct and indirect impacts on the health and well-being systems [6-8]. Following the aforementioned sanctions, Iran has confronted with various economic challenges in recent years such as reducing the oil exports and related revenues, banning the banks from international transactions, and restricting the imports including medicines and medical equipment, as well as devaluating the national currency and jumping the inflation rate. As a result, the sanction regime negatively affected almost all dimensions of Iran's heath sector, including physical rehabilitation services $[9,10]$.

A major proportion of patients using physical rehabilitation services (including physiotherapy, occupational therapy, Orthotics and Prosthetics) are categorized as vulnerable groups that the sanctions and the ad hoc economic recession may have significant adverse effects on their utilization [11]. For instance, reports have demonstrated the negative impacts of Greece's economic recession on the accessibility of treatment for multiple sclerosis and rheumatoid arthritis patients [12]. Therefore, monitoring and measuring the effects of sanctions and embargos on the physical rehabilitation sector and its targeted population can be a crucial strategy to develop comprehensive policies in order to diminish the current burdens.

In Iran, population aging, high rate of traffic injuries (amputations, fractures, and head trauma), chronic diseases, congenital disorders, natural disasters, and also climate changes, have increased the demand for physical rehabilitation services significantly $[13,14]$. Nonetheless, previous studies reported several barriers, including financial hardships and shortage of materials as the results of international sanctions [7, 9], which might prevent equitable utilization. Therefore, based on the United Nations (UN) and the World Health Organization (WHO) guidelines and instructions, strengthening the physical rehabilitation in health systems and also facilitating the availability and accessibility of these services for the targeted population, especially disabled people, should be considered through the decision- and policy-making processes, both nationally and internationally [15-17].

To the best knowledge, although several studies have been conducted regarding the impacts of international sanctions on different parts of the Iranian health sector $[1-3,6,18-23]$, there is no study that has evaluated the potential impacts of sanctions on physical rehabilitation functions in Iran.

In response, this qualitative study was conducted to investigate the situation of the physical rehabilitation sector in Iran after the international sanctions. The findings could also be used by international organizations to diminish the adverse effects of embargos on vulnerable populations such as disabled.

\section{Methods}

This qualitative study was conducted from January 2019 to June 2019 in Iran as a part of the Ph.D.'s thesis of Health Policy Degree requirement by the S.SH (first author). Decision- and policy-makers, rehabilitation experts, faculty members, and practitioners (including Physiotherapists, Occupational therapists, and Orthotists/Prosthetists), were selected to participate in indepth semi-structured interviews.

\section{Participants}

Purposive and snowball sampling approaches were used to identify the participants. During the sampling, the research team tried to recruit individuals with a maximum variation in terms of specialty, employment status, gender, experience, and geographic location. The eligibility criteria for semi-structured interviews were to include: (1) health policy-makers and rehabilitation experts who had more than 3 years of executive experience in policymaking in regard to the physical rehabilitation services in Iran; (2) faculty members who had at least 3 years of experience in regard to clinical and theoretical education of physical rehabilitation; and finally, (3) practitioners 
who had at least 4 years of experience of providing physical rehabilitation services in practice, along with a valid registration number of the Medical Council of the Islamic Republic of Iran (IRIMC). The interview sessions continued until saturation was achieved, and no new information was generated. Two sessions with duplicate information were determined to confirm the data saturation.

\section{Data collection}

In-depth semi-structured interviews were conducted by S.SH (a male Ph.D. Health Policy Candidate with healthrelated rehabilitation experiences) applying an interview guide including open-ended questions and suggested probes, developed based on the six-building block WHO framework (Table 1), which covers different dimensions of health system and provides a common language [24]. The primary questions were revised for further clarity based on the reflected feedbacks from initial interviews. Face-to-face interviews were conducted in big cities including Tehran, Shiraz, and Isfahan, and telephone and WhatsApp interviews were used for participants who lived in other cities or preferred it. Interviews were conducted in noiseless and favorable rooms, without any observer. The interviewer strived to ensure a high level of privacy to enable the participants to express their opinions freely. Besides two recorders were used for

Table 1 Interview guide

\section{Questions}

1. What are the effects of international sanctions and embargos on the provision of physical rehabilitation services (physiotherapy, occupational therapy, orthotics, and prosthetics) in Iran?

Probes: How? Your experience?

2. What are the effects of international sanctions and embargos on the financing of physical rehabilitation services (physiotherapy, occupational therapy, orthotics, and prosthetics) in Iran?

Probes: How? Your experience?

3. What are the effects of international sanctions and embargos on the governance and leadership of physical rehabilitation services

(physiotherapy, occupational therapy, orthotics, and prosthetics) in Iran?

Probes: How? Your experience?

4. What are the effects of international sanctions and embargos on the essential equipment and devices of physical rehabilitation services (physiotherapy, occupational therapy, orthotics, and prosthetics) in Iran?

Probes: How? Your experience?

5. What are the effects of international sanctions and embargos on the education and human workforce of physical rehabilitation services (physiotherapy, occupational therapy, orthotics, and prosthetics) in Iran?

Probes: How? Your experience?

6. What are the effects of international sanctions and embargos on the information systems of physical rehabilitation services (physiotherapy, occupational therapy, orthotics, and prosthetics) in Iran?

Probes: How? Your experience? discussions, taking notes was done during the interview simultaneously. Immediately after each interview, recorded files were transcribed verbatim by S.SH, and then, the transcribed files were saved in Word Microsoft Office. All participants were allowed to assess their interview texts, and if required, they had the opportunity to amend it. The first author endeavored to provide the transcript up to 14 days after each interview. To secure the anonymity, a pseudonym was applied for naming the participants in initial texts and publications.

To enhance the quality of reporting, the consolidated criteria for reporting qualitative research (COREQ) [25] and the standards for reporting qualitative research (SRQR) [26] were considered.

\section{Data analysis}

Framework analysis approach was used to investigate the situation of the physical rehabilitation sector in Iran after the international sanctions as perceived by policymakers, faculty members, and practitioners [27]. The analysis process was done along with the data collection process. Two of the authors (S.SH. and A.A.) read the transcripts several times independently. According to the framework analysis approach, the texts were divided into meaning units, and then, these identified units were condensed to develop codes and following sub-themes. At last, the research team discussed the sub-themes and also abstracted them to allocate the parent themes. Social Determinants of Health (SDH) framework, which has developed by Healthy People 2020 initiative, was applied to facilitate the analysis stages [28]. This framework consists of five constructs that can affect the health status and outcomes (Fig. 1). Disagreements among the authors were resolved through discussion.

Critical reflexivity was considered through data collection and analysis processes to diminish the potential risk of bias [29]. S.SH as the interviewer described his scientific and employment background at the beginning of each interview. Additionally, the involved authors in the analysis process had different scientific experiences that could reduce bias.

\section{Trustworthiness strategies}

Based on the Lincoln and Guba framework, trustworthiness is the vital parameter for evaluating the rigor of qualitative findings. This framework includes dependability, credibility, confirmability, transferability, and authenticity [30]. In this study, several measures were adopted to improve the trustworthiness of findings as follows: stepwise replication in data analysis to improve the dependability, peer debriefing, prolonged immersion of the first author, and methods triangulation to improve the credibility, member-checking by authors and participants to improve the confirmability, and in-depth 


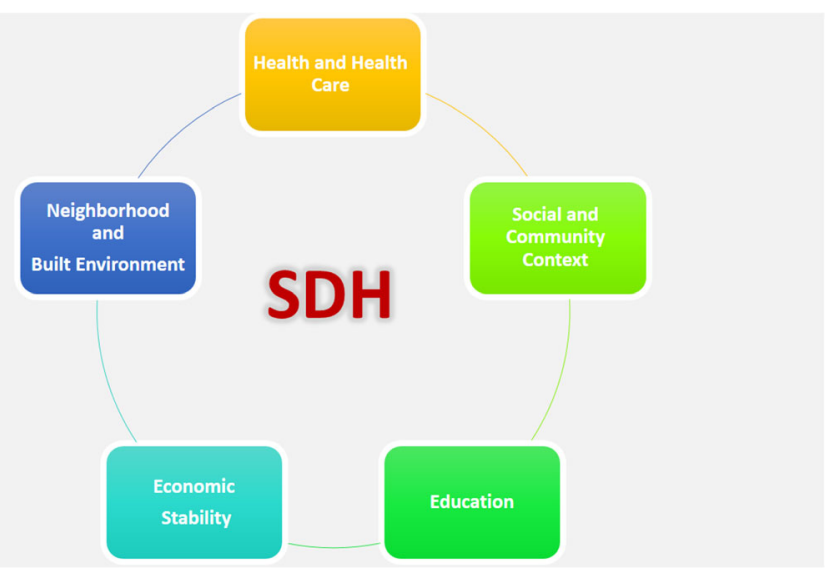

Fig. 1 Social determinants of health framework (adapted from: Healthy People 2020: Social Determinants of Health)

descriptions and purposive sampling to improve the transferability, and in final, considering citations from different participants to improve the authenticity.

\section{Ethical approval}

All participants were invited to involve in the interviews through introductory WhatsApp and e-mail letter including the objectives and aims of the project. All participants were free to withdraw from the study at any stage. Each participant received a written information sheet in Persian and was asked to read, and then, sign the consent form. Additionally, consent was achieved verbally at the first of each interview session. Ethical approval was provided by the Research Ethics Committee of the School of Health Management and Information Sciences, Iran University of Medical Sciences, Tehran, Iran (IR/IUMS/REC/1397/889).

\section{Results}

In total, 38 participants, including 11 health-policy makers, 7 rehabilitation experts, 8 faculty members, and 12 practitioners, involved in the study (Table 2). However, due to the employment status, a female practitioner declared not to participate in the study.

Through the interviews, participants pointed to a number of challenges facing the Iranian physical rehabilitation sector during the international sanctions

Table 2 Composition of participants

\begin{tabular}{ll}
\hline Participants & No. \\
\hline Health policy-maker & 11 \\
Faculty member & 8 \\
Rehabilitation expert & 7 \\
Physiotherapist & 5 \\
Orthotist/Prosthetist & 4 \\
Occupational therapist & 3 \\
\hline
\end{tabular}

period. The following explains the situation of this sector after the imposition of sanctions in accordance with the SDH framework in detail, and also, quotes from the in-depth interviews will be used for further clarity (Table 3).

\section{Socio-economic challenges}

The findings demonstrated that the international sanctions reduced the Iranian oil's export and revenues, as the main source of financing of health care and wellbeing services significantly. Many health decision- and policy-makers suggested that there are no sufficient funds for effective financing of physical rehabilitation services following the harsh sanctions. For example, one policy-maker stated:

"Much of the [Iranian] health and welfare system's budget comes from oil and petrochemical sales. In recent years, government revenues have fallen sharply. The government is trying to divide existing financial resources among different sectors. It is natural not to devote specific [financial] resources for the rehabilitation!"(Health policymaker 3)

Many participants identified the sharp rising inflation rate as the other negative impact of international sanctions, which can put various barriers in the way of optimal financing. The results showed that as inflation increased, health insurers' expenditures increased sharply, so some insurance companies were struggling to remove some services such as rehabilitation from their list of covered services.

"So our costs have increased. We have to cover essential health services and not include any services like physiotherapy."(Health policy-maker 6) 
Table 3 Themes, sub-themes, and suggested quotes

\begin{tabular}{|c|c|c|}
\hline Themes & Sub-themes & Quotes \\
\hline \multirow[t]{6}{*}{$\begin{array}{l}\text { Socio- } \\
\text { economic } \\
\text { challenges }\end{array}$} & Inadequate funding & $\begin{array}{l}\text { "Much of the [Iranian] health and welfare system's budget comes from oil and } \\
\text { petrochemical sales. In recent years, government revenues have fallen sharply..." (Health } \\
\text { policy-maker 3) }\end{array}$ \\
\hline & Rising inflation rate & $\begin{array}{l}\text { "So our costs have increased. We have to cover essential health services and not include any } \\
\text { services like physiotherapy." (Health policy-maker 6) }\end{array}$ \\
\hline & High unemployment rate & $\begin{array}{l}\text { "Our insurance funds are really in trouble. After the sanctions, many have become } \\
\text { unemployed. They don't even pay a premium!" (Health policy-maker 1) }\end{array}$ \\
\hline & Catastrophic expenditures & $\begin{array}{l}\text { "After the sanctions, prostheses have become really expensive. How can an amputee who } \\
\text { often has no income pay around } 120 \text { million Rials [Iranian currency] for a below-knee pros- } \\
\text { thesis?" (Practitioner 9) }\end{array}$ \\
\hline & $\begin{array}{l}\text { Inappropriate employment status of } \\
\text { practitioners }\end{array}$ & $\begin{array}{l}\text { "Rental rates for a clinic have gone up. Many of my colleagues have closed down. Not really } \\
\text { economical. The inflation of sanctions has destroyed us." (Practitioner 10) }\end{array}$ \\
\hline & & $\begin{array}{l}\text { "We have no job opportunities in other countries... But if there is some kind of international } \\
\text { cooperation right now, the credibility of our degree will increase." (Practitioner 4) }\end{array}$ \\
\hline \multirow[t]{2}{*}{$\begin{array}{l}\text { Education } \\
\text { challenges }\end{array}$} & $\begin{array}{l}\text { Decreasing the international } \\
\text { collaboration }\end{array}$ & $\begin{array}{l}\text { "Because of the sanctions, our department's collaboration with other universities around the } \\
\text { world has diminished. We used to exchange doctoral students. The students had very good } \\
\text { experiences that were very valuable for the development of the field [occupational therapy]." } \\
\text { (Faculty member 8) }\end{array}$ \\
\hline & $\begin{array}{l}\text { Shortage of training devices and } \\
\text { materials }\end{array}$ & "After the sanctions, we do not have many advanced training tools" (Faculty member 3) \\
\hline $\begin{array}{l}\text { International } \\
\text { challenges }\end{array}$ & $\begin{array}{l}\text { Rising challenges for patients from } \\
\text { neighborhood countries }\end{array}$ & $\begin{array}{l}\text { "Many amputees came here from Afghanistan and received prostheses. But now that our } \\
\text { raw materials are reduced, we can't provide them with services." (Rehabilitation expert 2) }\end{array}$ \\
\hline \multirow[t]{6}{*}{$\begin{array}{l}\text { Service delivery } \\
\text { challenges }\end{array}$} & $\begin{array}{l}\text { Shortage of raw materials for producing } \\
\text { the orthoses and prostheses }\end{array}$ & $\begin{array}{l}\text { "Although we work in a non-governmental organization, after the U.S. sanctions, there are } \\
\text { not many devices. We used artificial foot, produced by a German company named Ottobock } \\
\text { for below-knee amputees, the patients were very happy, but now we have to use Chinese } \\
\text { low-quality feet. After a few days, the foot will break!" (Practitioner 4) }\end{array}$ \\
\hline & $\begin{array}{l}\text { Hardening of the importing the needed } \\
\text { equipment }\end{array}$ & $\begin{array}{l}\text { "We needed some devices like Shock wave therapy, but we couldn't import them. } \\
\text { Interestingly, some equipment is only available in large cities." (Practitioner 9) }\end{array}$ \\
\hline & Inappropriate infrastructures & $\begin{array}{l}\text { "The rehabilitation infrastructures are really worn out, especially in the government sector. } \\
\text { The facilities of the State Welfare Organization were from twenty to thirty years ago. Many } \\
\text { facilities and features have not been updated. These sanctions have greatly restricted our } \\
\text { works." (Rehabilitation expert 4) }\end{array}$ \\
\hline & & $\begin{array}{l}\text { "Many of our tools are outdated. For example, we were not given the technology of new } \\
\text { orthoses. We are still building an orthosis that has been around for the past twenty years." } \\
\text { (Practitioner 8) }\end{array}$ \\
\hline & Impossibility to use external assistance & $\begin{array}{l}\text { "Many international organizations, such as the World Health Organization, the United } \\
\text { Nations, and others, allocate large funds annually for the services of disadvantaged groups } \\
\text { such as the disabled and the elderly, but because we are sanctioned, these resources are not } \\
\text { allocated to us..." (Rehabilitation expert 5) }\end{array}$ \\
\hline & & $\begin{array}{l}\text { "We tried to use the services of international accreditation agencies to improve the quality of } \\
\text { services, but they said that you are sanctioned and we are not going to cooperate with you } \\
\text {..." (Rehabilitation expert 1) }\end{array}$ \\
\hline
\end{tabular}

Increased unemployment rate is another factor that directly and indirectly affects the financing of the health system, including rehabilitation services. The high unemployment rate has dramatically reduced the premiums collected by health insurers.

"Our insurance funds are really in trouble. After the sanctions, many have become unemployed. They don't even pay a premium!"(Health policymaker 1)

In addition, the majority of providers described that following the recent sanctions and ad hoc economic pressures, the reimbursement period has been very long. Therefore, providers had to consider the patient direct payments as the main source.

"Insurance has not yet paid last year's invoice. Well ... how do I cover the costs? I have to receive out-ofpocket (OOP) payments." (Practitioner12)

These direct payments have confronted many households with catastrophic expenditures and led some households to go below the poverty line. Indeed, the high cost of rehabilitation services to recipients, and since many recipients are chronically disabled and also 
come from low-income families, the economic burden is multiplied.

"After the sanctions, prostheses have become really expensive. How can an amputee who often has no income pay around 120 million Rials [Iranian currency] for a below-knee prosthesis?" (Practitioner 9)

On the other hand, the harsh economic situation following the imposition of the sanctions has affected the employment status of physiotherapy, occupational therapy, and orthotics and prosthetics graduates. Practitioners demonstrated that following the sanctions, government employment has declined significantly and private employment has been very difficult due to inflation and rising costs, thus, many private rehabilitation centers closed in recent months.

"Rental rates for a clinic have gone up. Many of my colleagues have closed down. Not really economical. The inflation of sanctions has destroyed us." (Practitioner 10)

The declined strength of Iranian non-governmental organizations (NGOs) and charities following the devaluation of the national currency and declined in economic growth, was another challenge identified by the policymakers that has encountered many vulnerable groups with considerable obstacles.

"Many rehabilitation services were provided to disabled people through charities and disease associations. But in recent years, because of the poor economic situation, the resources of these institutions have also declined."(Faculty member 7)

\section{Education challenges}

Based on the findings of the study, academic education of physical rehabilitation disciplines (such as physiotherapy, occupational therapy, orthotics and prosthetics) has been strongly affected after international sanctions, which can curtail the scientific progress in this domain. Rejection of relevant articles by some journals, inability to attend the international scientific meetings and paying the registration fee, decreasing the international collaboration among relevant faculties and student exchange, and also lack of access to international training courses, were the most common challenges expressed.

"Because of the sanctions, our department's collaboration with other universities around the world has diminished. We used to exchange doctoral students. The students had very good experiences that were very valuable for the development of the field [occupational therapy]." (Faculty member 8)

Many participants also perceived challenges with regard to the physical rehabilitation human resources after the sanctions. The shortage of training devices and materials and also the lack of sufficient funds for clinical courses were identified.

"The budget for our department has declined sharply. Therefore, we are not able to provide the necessary equipment. The result is a decline in the quality of graduates." (Faculty member 2)

\section{International challenges}

These sanctions and embargos had also negative effects on patients from other countries who received rehabilitation services such as orthoses and prostheses in Iran. Due to the war and internal conflicts in many parts of the Middle East region, demands for physical rehabilitation services are rising. Therefore, some patients come to Iran for rehabilitation services, especially for artificial limbs. However, following the imposition of new sanctions, and problems arisen, these patients have faced serious challenges.

"Many amputees came here from Afghanistan and received prostheses. But now that our raw materials are reduced, we can't provide them with services." (Rehabilitation expert 2)

\section{Service delivery challenges}

Regarding the delivery of physical rehabilitation services, several challenges were described by participants, such as the shortage of raw materials for producing the orthoses and prostheses. A Prosthetist who worked in Iranian Red Crescent Society, criticized the U.S. sanctions and mentioned the shortage of crucial materials for producing the optimal prostheses.

\section{"Although we work in a non-governmental organization, after the U.S. sanctions, there are not many devices. We used artificial foot, produced by a German company named Ottobock for below-knee amputees, the patients were very happy, but now we have to use Chinese low-quality feet. After a few days, the foot will break!" (Practitioner 4)}

Participants pointed to the difficult, costly, and lengthy process of importing the needed equipment, due to the banned bank transaction following the international suctions against Iran. They believed that this situation has made many of the equipment needed to provide services unavailable, especially in outlying areas. 
"We needed some devices like Shock wave therapy, but we couldn't import them. Interestingly, some equipment is only available in large cities." (Practitioner 9)

A number of policy-makers expressed that the sanctions have reduced the Iranian health sector's capacities resulting in the neglect of physical rehabilitation services. In addition, a rehabilitation expert believed that since the health sector infrastructures are not well developed, the main proportion of health care services is not provided, especially rehabilitation interventions which need governmental supports.

"The rehabilitation infrastructures are really worn out, especially in the government sector. The facilities of the State Welfare Organization were from twenty to thirty years ago. Many facilities and features have not been updated. These sanctions have greatly restricted our works."(Rehabilitation expert 4)

Furthermore, corrupt activities in the provision of services were other mentioned pitfalls. Through the interviews, participants described corruption as one of the outcomes of sanctions. They believed that the imposed limitations have led to abuse by some providers. One university professor expressed it as follows:

"The shortage of some equipment has incited the clinics to sour the prices as much as they desire." (Faculty member 2)

A major proportion of available devices and equipment are outdated. Therefore, the quality of interventions has been reduced in recent years. One Orthotist reported this as follows:

"Many of our tools are outdated. For example, we were not given the technology of new orthoses. We are still building an orthosis that has been around for the past twenty years." (Practitioner 8)

The use of external assistance is one of the common ways of providing rehabilitation services to disabled people, especially in developing countries. Nonetheless, Iran's rehabilitation sector cannot benefit from these opportunities because of the banking restrictions.

"Many international organizations, such as the World Health Organization, the United Nations, and others, allocate large funds annually for the services of disadvantaged groups such as the disabled and the elderly, but because we are sanctioned, these resources are not allocated to us ... "(Rehabilitation expert 5)

In addition, the declined strength of Iranian nongovernmental organizations (NGOs) and charities following the devaluation of the national currency and declined in economic growth, was another challenge identified by the policy-makers that has encountered many vulnerable groups with considerable obstacles.

"Many rehabilitation services were provided to disabled people through charities and disease associations. But in recent years, because of the poor economic situation, the resources of these institutions have also declined."(Faculty member 7)

Rehabilitation experts expressed that failure to use the foreign accredited institutions is another negative impact of international sanctions on the governance of physical rehabilitation services in Iran. Indeed, almost all of the accreditation institutes such as the Commission on Accreditation of Rehabilitation Facilities (CARF), are not allowed to cooperate with the Iranian physical rehabilitation sector.

"We tried to use the services of international accreditation agencies to improve the quality of services, but they said that you are sanctioned and we are not going to cooperate with you ..."(Rehabilitation expert 1)

Furthermore, due to sanctions and lack of reputable dealers, many of the imported equipment are also sold in cash in Iran. However, in many countries around the world, this equipment is provided with long-term installments by reputable dealers.

"Rehabilitation equipment is expensive. On the other hand, after the sanctions, the dealerships are out of the country and we have to buy the equipment in cash ..." (Faculty member 7)

Lack of a valid warranty for equipment and devices is another challenge. Many practitioners believed that there are not adequate instructions on how to use the device. Also, it can be very difficult to repair when the device crashes.

"There are a lot of things [devices] in our center right now that are broken. No one knows how to repair them. The dealership that we bought from them has also closed." (Practitioner 11)

In despite these, during the interviews, the participants stated that the development of Knowledge enterprises 
and also the use of reverse engineering approaches has provided opportunities for domestic production of the required devices and technologies.

\section{"Recently, with the development of knowledge-based companies, some devices have been developed by ex- perts in these companies." (Rehabilitation expert 2)}

Many policy-makers mentioned the shortage of comprehensive monitoring services to follow-up the interventions' effects. In fact, since international sanctions have banned the import of modern technologies, the physical rehabilitation sector information system is affected.

"There are many good tools for monitoring and evaluating interventions, but we cannot import because we are sanctions."(Health policy-maker 6)

Although using telerehabilitation platforms for providing the physical rehabilitation services in remote areas has been considered in recent years, the lack of relevant equipment and technologies have prevented applying these provision approaches.

"We would have liked to use telerehabilitation and telemedicine for remote areas, but [relevant experts] said the equipment needed was imported and could not be accessed after the boycott."(Health policy-maker 11)

\section{Discussion}

This study is the first study to investigate the situation of Iranian physical rehabilitation sector after the imposition of international sanctions. The findings would suggest that the sanctions and embargoes had significant adverse effects on physical rehabilitation sector. Participants expressed a number of challenges of imposed sanctions in terms of main dimensions of $\mathrm{SDH}$ framework.

Financing is another functions of Iranian physical rehabilitation sector which was affected meaningfully. Based on the evidence, Iran's gross domestic product (GDP) and also economic growth rate have reduced sharply, which led to a range of limitations in health and welfare funding [2]. In accordance with the government's reports, only one-sixth of the Disability Protection Act budget has been allocated. Therefore, OOP payments are the common mechanism of payment for health care services, especially physical rehabilitation [31]. As a result, a significant proportion of households has confronted with CEs and also refuse to receive services [7]. In addition, policy-makers and providers demonstrated the negative impacts of high rate of inflation on the price of raw materials and equipment as well as rental rates. The other studies also have reported the adverse impacts of sanction-borne inflation on health sector and its sub-systems funding [21, 32]. As a whole, disabled and chronically ill patients who make up a large portion of physical rehabilitation recipients, are most affected following economic crisis. For instance, after the economic recession, vulnerable groups had limited access to health care services in Greece, Honduras, Iraq, and Syria [12, 33-36]. These findings are in agreement with a UNICEF statement which reported that most vulnerable and least culpable groups endure the heaviest consequences [37].

Furthermore, academic education of physical rehabilitation disciplines was another main domain affected during the international sanctions. Although the World Medical Association (WMA) rejects any academic sanction [38], limitations against scientific articles, attending scientific meetings, and international collaborations were commonly identified challenges through interviews. A recent publication concluded that the academic boycotts and sanctions can curtail the researchers' progress and freedom [21]. Finally, since the international cooperation was reduced in recent years, information and accreditation systems have not developed in physical rehabilitation sector. Therefore, in some cases, the interventions have not sufficient quality [39]. This problem has been observed in Iranian medicine sector, which many international companies are refusing to cooperate and supply medicine to Iran [40, 41].

The shortage of raw materials and equipment was identified as the main challenge during the sanctions. Since imports had fallen sharply, the imported materials were scarcely available [23]. Further, the prices of raw materials and equipment raised considerably, sometimes doubled or tripled. In response to this situation, using low-quality materials produced in Iran or imported from eastern countries, became the common strategy $[7,19]$. Therefore, a major proportion of clients such as amputees has been deprived of equitable and safe access to services. More importantly, through the interview sessions, the consequences of sanctions along with the poor management were considered to be potentially related to corruption in the provision of physical rehabilitation services, especially, physiotherapy and orthotics/prosthetics. A recent study also reported that corrupt activities are more prevalent in sanctioned nations [42]. Another notable finding was the adverse impacts of sanctions on patients from neighboring countries. Regarding the war and internal conflicts in Middle-East region, the demand for physical rehabilitation services has increased during the past decades [43]. Consequently, a large number of injured people from Afghanistan, Iraq, Syria and Yemen, come to Iran to 
receive rehabilitation services. However, in recent years and after the sanctions were tightened, they have faced serious problems [44].

\section{Limitations}

Our study has several limitations; firstly, only one author (SSH) conducted the interviews, which can have influenced the quality of raw data. Secondly, the data was restricted to semi-structured interviews and would gain more advantage from a quantitative survey. Thirdly, based on the predefined protocol, patients/clients were not included in this study, who could provide good information. Lastly, since the sanctions regimes are international macro policies, it is difficult to draw a clear straightforward cause and effect relationship with regard to their effects on the studied field, and only a description of the situation was presented.

\section{Conclusions}

International sanctions and embargos had considerable multifaceted effects on the Iranian physical rehabilitation sector. Possibly, disabled and vulnerable groups who usually belong to the poor population, have confronted with harsh barriers to access the physical rehabilitation services. In addition, the current sanctions against Iran had also negative impacts on the utilization of these services by relevant patients who come from neighboring countries to receive them. Therefore, the international community must be aware of these effects and be concerned about their irreparable consequences, and work to end them.

\section{Abbreviations \\ JCPOA: Joint Comprehensive Plan of Action; UN: United Nations; WHO: World Health Organization; COREQ: Consolidated criteria for reporting qualitative research; SRQR: Standards for reporting qualitative research; CEs: Catastrophic expenditures; NGOs: Non-governmental organizations; CARF: Commission on Accreditation of Rehabilitation Facilities; GDP: Gross domestic product; OOP: Out-of-pocket}

\section{Acknowledgements}

We would like to thank the study participants.

\section{Authors' contributions}

$\mathrm{SSH}, \mathrm{AA}, \mathrm{HSH}$ and MK conceptualized and designed the study. SSH and AA collected data. SSH, AA, HSH, and MK involved in analysis process. SSH, PM, and $\mathrm{KBL}$ contributed to the first draft. All authors contributed to the final draft. The authors read and approved the final manuscript.

\section{Funding}

The author(s) received no financial support for the research, authorship, and/ or publication of this article.

\section{Availability of data and materials}

The data collected and analyzed during the study are available from the corresponding author on reasonable request.

\section{Ethics approval and consent to participate}

The Ethics committee of the Iran University of Medical Sciences (IUMS) has confirmed the study protocol (IR-IUMS-REC-1397-889). Written informative consent approval was gained prior to interviews.
Consent for publication

Not applicable.

\section{Competing interests}

The authors declare that they have no competing interests.

\section{Author details}

${ }^{1}$ Health Policy Research Center, Institute of Health, Shiraz University of Medical Sciences, Shiraz, Iran. ${ }^{2}$ Department of Health Services Management, School of Health Management and Information Sciences, Iran University of Medical Sciences, Tehran, Iran. ${ }^{3}$ Population Health Sciences Institute, Newcastle University, Newcastle, UK. ${ }^{4}$ Rehabilitation Research Center, Department of Rehabilitation Management, School of Rehabilitation Sciences, Iran University of Medical Sciences, Tehran, Iran. ${ }^{5}$ Iran-Helal Institute of Applied Science and Technology, Tehran, Iran.

Received: 21 April 2020 Accepted: 11 September 2020

Published online: 23 September 2020

\section{References}

1. Setayesh S, Mackey TK. Addressing the impact of economic sanctions on Iranian drug shortages in the joint comprehensive plan of action: promoting access to medicines and health diplomacy. Glob Health. 2016;12(1):31.

2. Aloosh M, Salavati A, Aloosh A. Economic sanctions threaten population health: the case of Iran. Public Health. 2019;169:10-3.

3. Kokabisaghi F. Assessment of the effects of economic sanctions on Iranians' right to health by using human rights impact assessment tool: a systematic review. Int J Health Policy Manag. 2018;7(5):374.

4. Danaei G, Harirchi I, Sajadi HS, Yahyaei F, Majdzadeh R. The harsh effects of sanctions on Iranian health. Lancet. 2019;394(10197):468-9.

5. Takian A, Raoofi A, Kazempour-Ardebili S. COVID-19 battle during the toughest sanctions against Iran. Lancet (London, England). 2020;395(10229):1035.

6. Shahabi S, Fazlalizadeh H, Stedman J, Chuang L, Shariftabrizi A, Ram R. The impact of international economic sanctions on Iranian cancer healthcare. Health Policy. 2015;119(10):1309-18.

7. Soltani S, Takian A, SARI AA, Majdzadeh R, Kamali M. Financial barriers to access to health Services for Adult People with disability in Iran: the challenges for universal health coverage. Iran J Public Health. 2019;48(3):508.

8. Massoumi RL, Koduri S. Adverse effects of political sanctions on the health care system in Iran. J Glob Health. 2015;5(2):020302. https://doi.org/10.7189/ jogh.05-020302.

9. Raeissadat SA, Bahrami MH, Rayegani SM, Hassanabadi H, Babaee M, Najafi S, Aghabozorgi R. Obstacles facing evidence based medicine in physical medicine and rehabilitation: from opinion and knowledge to practice. Electron Physician. 2017;9(11):5689.

10. Ardalan A, Sohmbizadeh S, Latifi M, Rajaei M, Asadi A, Mirbeigi S, Rouhi N, Yousefi $\mathrm{H}$. Responding to physical and psychological health impacts of disasters: case study of the Iranian disaster rehabilitation plan. East Mediterr Health J. 2016;22(3):212-8.

11. Soltani S, Takian A, Sari AA, Majdzadeh R, Kamali M. Cultural barriers in access to healthcare services for people with disability in Iran: a qualitative study. Med J Islam Repub Iran. 2017;31:51.

12. Souliotis K, Alexopoulou E, Papageorgiou M, Politi A, Litsa P, Contiades X. Access to care for multiple sclerosis in times of economic crisis in Greecethe HOPE II study. Int J Health Policy Manag. 2016;5(2):83.

13. Foroutaghe MD, Moghaddam AM, Fakoor V. Time trends in gender-specific incidence rates of road traffic injuries in Iran. PLoS One. 2019;14(5): e0216462. https://doi.org/10.1371/journal.pone.0216462.

14. Moradi-Lakeh M, Forouzanfar MH, Vollset SE, El Bcheraoui C, Daoud F, Afshin A, Charara R, Khalil I, Higashi H, El Razek MMA. Burden of musculoskeletal disorders in the eastern Mediterranean region, 1990-2013: findings from the global burden of disease study 2013. Ann Rheum Dis. 2017;76(8):1365-73.

15. Assembly UN General: Universal declaration of human rights. UN General Assembly 1948. http://www.ohchr.org/EN/UDHR/Documents/UDHR_ Translations/eng.pdf. Accessed 8 Sep 2020.

16. Assembly UG: International covenant on economic, social and cultural rights. United Nations, Treaty Series 1966, 993(3):2009-2057.

17. World Health Organization. Rehabilitation in health systems: guide for action. Geneva: World Health Organization; 2019.

18. Hassani M. Impact of sanctions on cancer care in Iran. Arch Bone Jt Surg. 2018;6(4):248 
19. Hosseini SA. Impact of sanctions on procurement of medicine and medical devices in Iran; a technical response. Arch Iran Med. 2013;16(12):736-8.

20. Karimi M, Haghpanah S. The effects of economic sanctions on disease specific clinical outcomes of patients with thalassemia and hemophilia in Iran. Health Policy. 2015;119(2):239-43.

21. Kokabisaghi F, Miller AC, Bashar FR, Salesi M, Zarchi AA, Keramatfar A, Pourhoseingholi MA, Amini H, Vahedian-Azimi A. Impact of United States political sanctions on international collaborations and research in Iran. BMJ Glob Health. 2019;4(5):e001692.

22. Baradaran-Seyed Z, Majdzadeh R. Economic sanctions strangle Iranians' health, not just drug supply. Lancet. 2013;381(9878):1626.

23. Shariatirad S, Maarefvand M. Sanctions against Iran and the impact on drug use and addiction treatment. Int J Drug Policy. 2013;24(6):636-7.

24. Mounier-Jack S, Griffiths UK, Closser S, Burchett H, Marchal B. Measuring the health systems impact of disease control programmes: a critical reflection on the WHO building blocks framework. BMC Public Health. 2014;14(1):278.

25. Tong A, Sainsbury P, Craig J. Consolidated criteria for reporting qualitative research (COREQ): a 32-item checklist for interviews and focus groups. Int J Qual Health Care. 2007;19(6):349-57.

26. O'Brien BC, Harris IB, Beckman TJ, Reed DA, Cook DA. Standards for reporting qualitative research: a synthesis of recommendations. Acad Med. 2014;89(9):1245-51.

27. Gale NK, Heath G, Cameron E, Rashid S, Redwood S. Using the framework method for the analysis of qualitative data in multi-disciplinary health research. BMC Med Res Methodol. 2013;13(1):1-8.

28. Healthy People 2020: Social determinants of health. Office of Disease Prevention and Health Promotion. [https://www.healthypeople.gov/2020/ topics-objectives/topic/social-determinants-of-health]. .

29. Cho J, Trent A. Validity in qualitative research revisited. Qual Res. 2006;6(3):319-40.

30. Kyngäs H, Kääriäinen M, Elo S. The trustworthiness of content analysis. In: The application of content analysis in nursing science research. Berlin: Springer; 2020. p. 41-8

31. Shahabi S, Teymourlouy AA, Shabaninejad H, Kamali M, Lankarani KB. Financing of physical rehabilitation services in Iran: a stakeholder and social network analysis. BMC Health Serv Res. 2020;20(1):1.

32. Rezapour A, Azar FE, Aghdash SA, Tanoomand A, Ahmadzadeh N, Asiabar AS. Inequity in household's capacity to pay and health payments in TehranIran-2013. Med J Islam Repub Iran. 2015;29:245

33. Piette JD, Mendoza-Avelares MO, Chess L, Milton EC, Reyes AM, Rodriguez-Saldaña J. Report on Honduras: ripples in the pond - the financial crisis and remittances to chronically ill patients in Honduras. Int J Health Serv. 2012;42(2):197-212.

34. El Bcheraoui C, Jumaan AO, Collison ML, Daoud F, Mokdad AH. Health in Yemen: losing ground in war time. Glob Health. 2018;14(1):42.

35. Garfield R. The public health impact of sanctions: contrasting responses of Iraq and Cuba. Middle East Rep. 2000;215:16-9.

36. Javan-Noughabi J, Sadeghi A, Rezapour A. Impact of the economic crisis on healthcare resources: a panel data analysis in eastern Mediterranean countries during 2005 to 2013. Clin Epidemiol Glob Health. 2019;7(1):98-101.

37. Garfield R, Devin J, Fausey J. The health impact of economic sanctions. Bull N Y Acad Med. 1995;72(2):454.

38. Rezaee-Zavareh MS, Karimi-Sari H, Alavian SM. Iran, sanctions, and research collaborations. Lancet. 2016;387(10013):28-9.

39. Abdi K, Arab M, Rashidian A, Kamali M, Khankeh HR, Farahani FK. Exploring barriers of the health system to rehabilitation services for people with disabilities in Iran: a qualitative study. Electron Physician. 2015;7(7):1476.

40. Mirzaei S, Dadparvar S, Alavi A. Economic sanctions endanger nuclear medicine services in Iran. J Nucl Med. 2019;60(4):569-70.

41. Yousefi N, Moradi N, Dinarvand R, Ghiasi G, Inanloo H, Peiravian F. Policies to improve access to pharmaceutical products in shortage: the experience of Iran food and drug administration. Daru. 2019;27(1):169-77.

42. Kamali T, Mashayekh M, Jandaghi G. The impact of economic sanctions on corruption in target countries: a cross country study. World Sci News. 2016; 45(2):276-91.

43. Faber J, Saggurthi P. Physical rehabilitation services in Iraq. Lancet. 2013; 381(9870):881-3.

44. Bisaillon L, Gooshki ES, Briskman L. Medico-legal borders and the shaping of health services for afghans in Iran: physical, social, bureaucratic, and public health conditions of care. Int J Migr Bord Stud. 2016;2(1):40-58.

\section{Publisher's Note}

Springer Nature remains neutral with regard to jurisdictional claims in published maps and institutional affiliations.

\section{Ready to submit your research? Choose BMC and benefit from:}

- fast, convenient online submission

- thorough peer review by experienced researchers in your field

- rapid publication on acceptance

- support for research data, including large and complex data types

- gold Open Access which fosters wider collaboration and increased citations

- maximum visibility for your research: over $100 \mathrm{M}$ website views per year

At $\mathrm{BMC}$, research is always in progress.

Learn more biomedcentral.com/submissions 